\title{
Prodynorphin Peptide Immunocytochemistry in Rhesus Monkey Brain
}

\author{
HENRY KHACHATURIAN, MICHAEL E. LEWIS, SUZANNE N. HABER,* \\ RICHARD A. HOUGHTEN, $\dagger$ HUDA AKIL AND STANLEY J. WATSON \\ Mental Health Research Institute, University of Michigan, Ann Arbor, MI 48109 \\ *Department of Anatomy, University of Rochester, Rochester, NY 14642 \\ $\dagger$ †cripps Clinic and Research Institute, Department of Immunopathology, La Jolla, CA 92036
}

\begin{abstract}
KHACHATURIAN, H., M. E. LEWIS, S. N. HABER, R. A. HOUGHTEN, H. AKIL AND S. J. WATSON. Prodynorphin peptide immunocytochemistry in rhesus monkey brain. PEPTIDES 6: Suppl. 2, 155-166, 1985. - The present study describes the immunocytochemical distribution of peptides derived from the prodynorphin precursor in the brain of the rhesus monkey (Mac'aca mulatta). Animals were treated with colchicine (intracerebroventricularly) prior to perfusion to enhance the observation of perikaryal immunoreactivity. Using antisera generated against dynorphin $A(1-17)$, dynorphin $\mathrm{B}(1-13)$, and prodynorphin(186-208) (or bridge peptide), the anatomical distribution of dynorphin systems was mapped. The results indicate a widespread neuronal localization of immunoreactivity from the cerebral cortex to the caudal medulla. Anti-dynorphin B and anti-bridge peptide sera proved useful for the demonstration of neuronal perikarya, while the dynorphin A antiserum was best for localizing terminal projection fields. Immunoreactive perikarya are located in numerous brain loci, including the cingulate cortex, caudate nucleus, amygdala, hypothalamus (especially the magnocellular nuclei), thalamus, substantia grisea centralis, parabrachial nucleus, nucleus tractus solitarius, and other nuclei. In addition, fiber and terminal immunoreactivity are seen in varying densities in the striatum and pallidum, substantia innominata, hypothalamus, substantia nigra pars reticulata, parabrachial nucleus, spinal trigeminal nucleus, and other areas. The distribution of prodynorphin peptides in the brain of the monkey is similar to that described for the rat brain; however, significant differences also exist. Other interspecies differences in the anatomy of prodynorphin and proenkephalin neuronal systems in the monkey and human brain are further discussed.
\end{abstract}

Prodynorphin Dynorphin A Dynorphin B Bridge peptide Rhesus monkey Brain Immunocytochemistry

PEPTIDES derived from the prodynorphin precursor [23] include dynorphin $\mathrm{A}$, dynorphin $\mathrm{B}$ (or rimorphin), and $\alpha$-neo-endorphin $[11,13,15,24,31,48]$. The initial immunocytochemical observations of dynorphin distribution in the central nervous system demonstrated the coexistence of dynorphin $A(1-13)$ and arginine-vasopressin in the magnocellular neurons of the supraoptic and paraventricular nuclei as well as in nerve terminals in the neural lobe of the pituitary $[57,58]$. Similar observations were also made using antisera generated against $\alpha$-neo-endorphin $[61,65,66]$. Subsequently, we and other investigators were able to show dynorphin $\mathrm{A}$, dynorphin $\mathrm{B}$, and $\alpha$-neo-endorphin to be colocalized in neuronal perikarya in several regions of the forebrain and brain stem $[62,63]$, confirming the biochemical and molecular biological studies of the prodynorphin precursor [23].

Most previous immunocytochemical $[28,30,34,35,44$, $51,57-63,65-67]$ and radioimmunoassay $[2,4,5,8,12,14$, $22,37,39,40,41,64,69-73]$ studies of dynorphin distribution in the central nervous system have focused on its localization in the brain and spinal cord of rat. However, our knowledge of dynorphin anatomy in the primate brain is incomplete and has been limited to anatomical studies of opioid peptides in the human and monkey basal ganglia $[20,21]$ and opioid peptide-receptor relationships in rhesus monkey brain $[32,33]$, as well as radioimmunoassay studies of human and monkey central nervous system $[7,16,38,42,43,49]$. On the other hand, the enkephalins have been shown to be distributed widely in neuronal perikarya and fibers throughout the central nervous system of the African green monkey $[17,18]$. We have also recently described the distribution of $\beta$-endorphin and other peptides derived from proopiomelanocortin in the brain of the rhesus monkey [26]. In these latter studies of the distribution of enkephalins and $\beta$-endorphin in monkey brain, striking similarities have been noted with their distribution in rat brain $[27,29,35]$. However, some notable differences have also been observed $[17,26]$. Because of interspecies variation in the distribution of opioid peptides, as shown for other neuropeptides [9] as well as classical neurotransmitters [46], we have chosen to further investigate the immunocytochemical distribution of peptides derived from prodynorphin in the brain of the rhesus monkey and compare the present findings with those reported for the rat brain. Preliminary results from this study have been presented elsewhere [25].

\section{METHOD}

Brains from either normal $(n=1)$ or colchicine-pretreated $(n=5)$ adult rhesus monkeys (Macaca mulatta, housed individually at the University primate colony) were processed for peroxidase-antiperoxidase (PAP) immunocy tochemistry. 
Each animal was anesthetized by injection of sodium pentobarbital $(30 \mathrm{mg} / \mathrm{kg}$ ) into the saphenous vein at $9 \mathrm{a} . \mathrm{m}$. The animal was then transferred onto a surgical table and artificially respirated via an endotracheal tube. The rib cage was removed, and the pericardium excised. The left ventricular wall was slit open and a plastic cannula was inserted through the cavity of the left ventricle into the aorta and tied firmly in place with suture. The right atrium was punctured to allow for an open circulation, and then the cardiovascular system was flushed with two liters of normal saline through the aortic cannula. Immediately following this step, the animal was trans-aortically perfused with 16 liters of neutral-buffered $4 \%$ formaldehyde for approximately 30 minutes. The cannula was removed, the head was severed from the trunk, and the brain was removed and either cut stereotaxically in frontal or parasagittal planes, or postfixed intact for 24 hours in the same fixative. The tissue that was stereotaxically cut into 1 $\mathrm{cm}$ thick slices was further postfixed for 2-4 hours. These slices were then transferred into $15 \%$ sucrose in $0.02 \mathrm{M}$ phosphate-buffered saline (PBS) and stored for 24 hours at $4^{\circ} \mathrm{C}$. The tissue was frozen in $-50^{\circ} \mathrm{C}$ isopentane or liquid nitrogen, and stored at $-80^{\circ} \mathrm{C}$. The brain that was postfixed intact for 24 hours was immersed into successively higher concentrations of sucrose $(10,20,30 \%)$ for several days, each at $4^{\circ} \mathrm{C}$, until the tissue was completely penetrated by sucrose. This brain was used for floating-section immunocytochemistry.

\section{Frozen-Section Immunocytochemistry}

The frozen brain slices were stored at $-80^{\circ} \mathrm{C}$, placed in a cryostat set at $-20^{\circ} \mathrm{C}$, and sectioned at either 20 or $32 \mu \mathrm{m}$ and thaw-mounted onto subbed glass slides. The slides were also stored at $-80^{\circ} \mathrm{C}$. The sections to be processed for PAP immunocy tochemistry [30] were allowed to air dry and incubated with normal goat serum (NGS) (GIBCO) for $10 \mathrm{~min}$ utes at $37^{\circ} \mathrm{C}$. This solution was drained and replaced by primary rabbit antiserum raised against dynorphin $A(1-17)$, dynorphin $B(1-13)$, or porcine prodynorphin(186-208) (bridge peptide). All antisera were diluted in 0.02 M PBS containing $0.3 \%$ Triton $X-100$. After 1 hour incubation, the slides were placed in moist boxes and stored overnight at $4^{\circ} \mathrm{C}$. The next day, the sections were washed in several changes of PBS, incubated at $37^{\circ} \mathrm{C}$ with goat anti-rabbit serum (GAR) (Arnel) at 1:1000 dilution for 30 minutes, and again stored overnight at $4^{\circ} \mathrm{C}$. On the third day, the sections were washed in PBS and incubated with rabbit antiserum against horseradish peroxidase (HRP) at 1:200 dilution for 40 minutes followed by PBS wash and subsequent incubation with $4 \mu \mathrm{g} / \mathrm{ml}$ HRP enzyme (Sigma, type VI) for 40 minutes. After PBS wash, the sections were reacted in a solution of $0.125 \mathrm{mg} / \mathrm{ml}$ diaminobenzidine (Sigma) and $0.06 \%$ hydrogen peroxide for 15 minutes at room temperature. The sections were then rinsed in distilled water, briefly immersed into $0.01 \%$ osmium tetroxide, dehydrated through graded ethanols and xylenes, and coverslipped in Permount.

\section{Floating-Section Immunocytochemistry}

The brain was removed from $30 \%$ sucrose and placed on a sliding microtome, frozen with dry ice, and sectioned at $35-50 \mu \mathrm{m}$. The sections were stored in PBS at $4^{\circ} \mathrm{C}$ until processed for PAP immunocytochemistry [17]. Designated sections were transferred into marked incubation dishes and preincubated with 10\% NGS in Triton-PBS for 20-30 minutes. Subsequently, the sections were incubated with pri- mary rabbit antisera against dynorphin $A(1-17)$, dynorphin $\mathrm{B}(1-13)$, or dynorphin bridge peptide. Incubation was carried out at $4^{\circ} \mathrm{C}$ for approximately 72 hours with constant shaking. Then, the sections were washed in several changes of PBS and preincubated in NGS for 10 minutes followed by GAR (1:1000 dilution) incubation at $4^{\circ} \mathrm{C}$ overnight. Next, after several PBS washes, the sections were again preincubated in NGS for 10 minutes prior to incubation with PAP complex (Cappel) (1:500 dilution) for 1 hour at room temperature. Some sections were processed according to the procedure described in the previous section (i.e., HRP antibody followed by enzyme). After several PBS washes, the sections were rinsed in $0.05 \mathrm{M}$ Tris buffer $(\mathrm{pH} \mathrm{7.6)}$ and incubated in Tris buffer containing $0.5 \mathrm{mg} / \mathrm{ml}$ diaminobenzidine and $0.01 \%$ hydrogen peroxide for 20 minutes. This reaction was followed by several rinses in Tris buffer and then PBS, after which the sections were stored in $10 \%$ formalin until mounted onto subbed glass slides. For the latter, the sections were rinsed in distilled water and mounted in a solution of $0.5 \%$ gelatin in $40 \%$ ethanal. The slide-mounted sections were allowed to air dry and then were briefly osmicated with $0.2 \%$ osmium tetroxide, rinsed, dehydrated through graded ethanols, cleared in xylene, and mounted in Permount. Observations and photomicrographs were made using a Leitz microscope. The low-power photographs were made using a macroscope.

\section{Colchicine Treatment}

Several animals were pretreated with colchicine to enhance the observed perikaryal immunoreactivity. Since colchicine inhibits the synthesis of microtubules, it causes a retardation in axonal transport (see [47]), which results in an accumulation of synthesized peptides in neuronal perikarya and truncal axons [30]. Prior to this treatment, each animal was anesthetized with sodium pentobarbital injected into the saphenous vein. The head was fixed onto a stereotaxic apparatus, the skull exposed, and a hole drilled into the skull 8.0 $\mathrm{mm}$ anterior to bregma and $4.0 \mathrm{~mm}$ lateral to midline. Colchicine ( $75-600 \mu \mathrm{g} / \mathrm{kg}$ body weight) dissolved in $0.9 \%$ saline was drawn into a calibrated plastic tube attached to a cannula which was inserted through the hole directly into the right lateral cerebral ventricle $(19.6 \mathrm{~mm}$ deep $)$. The colchicine solution $(0.5 \mathrm{ml})$ was allowed to diffuse into the cerebrospinal fluid by gravity flow. The cannula was removed and the hole was filled with bone wax and the scalp sutured. In order to decrease the probability of seizures and maintain the comfort of the animal, each monkey was kept under sedation with intramuscular injections of valium $(5 \mathrm{mg} / \mathrm{ml})$ for 24 to 48 hours prior to perfusion as described above.

\section{RESULTS}

The antisera raised against dynorphin $A(1-17)$ and dynorphin $B(1-13)$ have been previously characterized [30, 59-62]. The anti-prodynorphin(186-208) or bridge peptide antiserum has also been extensively characterized in our laboratory. Under immunocytochemical conditions, each antibody used is highly specific for the peptide antigen against which it was raised, and can be blocked by $1 \mu \mathrm{M}$ concentration of that peptide. They could not, however, be blocked by other peptides tested in up to $50 \mu \mathrm{M}$ concentrations, including those which have amino acid sequences in common with the peptide antigen. For example, the immunoreactivity seen with the dynorphin $A(1-17)$ antiserum could be blocked by dynorphin $\mathrm{A}(1-17)$ and dynorphin $\mathrm{A}(1-8)$, but not by dynorphin 

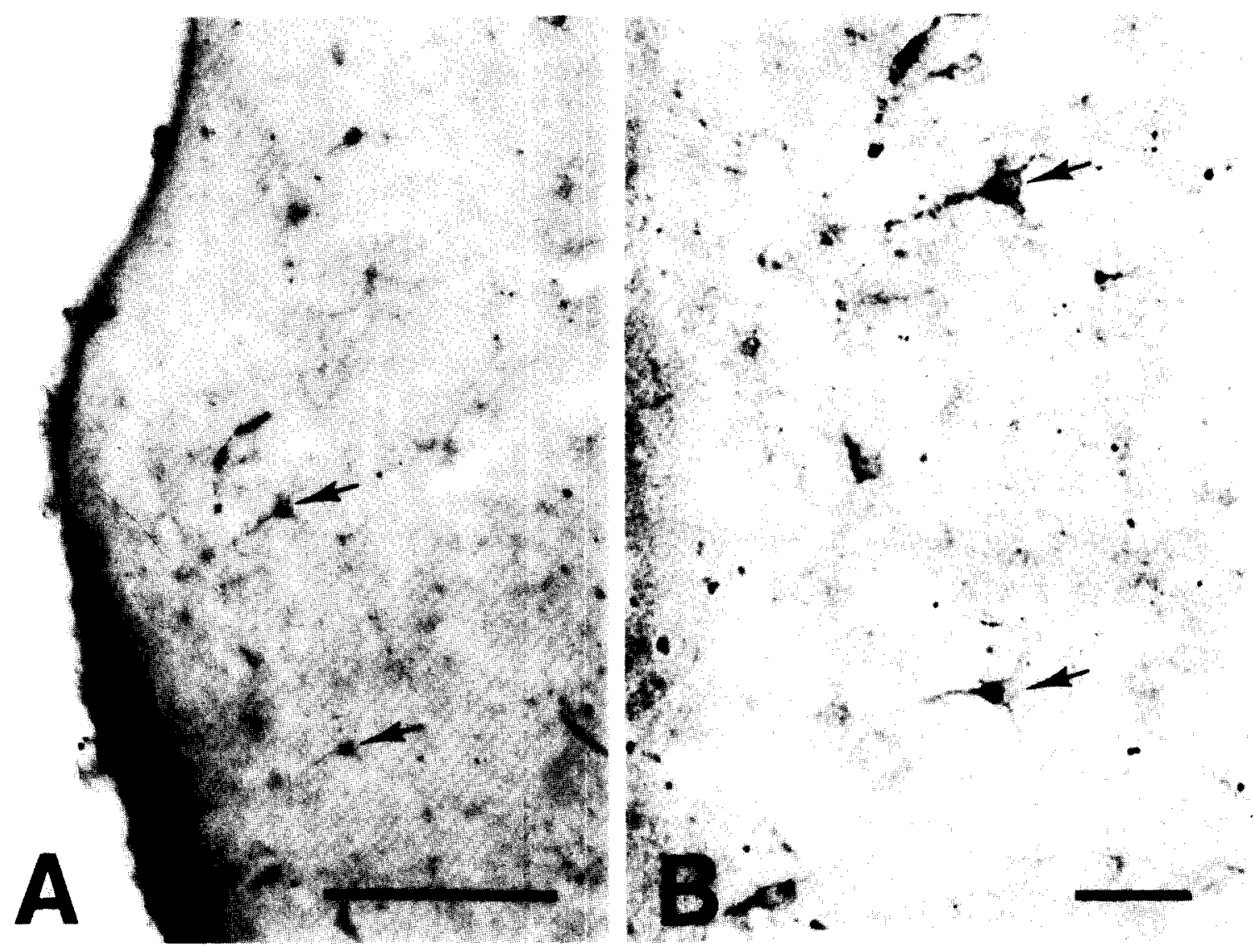

FIG. 1. Dynorphin B immunoreactive perikarya in the anterior cingulate cortex (subcallosal gyrus [33]). These small neurons are found in layers II and III. The arrows in panel A point to two neurons in layer II that are shown magnified in panel B. Bar (A) $=200 \mu \mathrm{m}$. Bar $(B)=50 \mu \mathrm{m}$.

$\mathrm{B}(1-13), \quad \alpha$-neo-endorphin, bridge peptide, Leuenkephalin, Met-enkephalin, BAM-22P, peptide E, proenkephalin(192-203), or $\beta$-endorphin. Likewise, the immunoreactivity observed using the dynorphin $B(1-13)$ antiserum was blockable by dynorphin $\mathrm{B}(1-13)$, but not by dynorphin $\mathrm{A}(1-17)$, dynorphin $\mathrm{A}(1-8), \quad \alpha$-neoendorphin, bridge peptide, Leu-enkephalin, Met-enkephalin, BAM-22P, peptide E, proenkephalin(192-203), or $\beta$-endorphin. The bridge peptide immunoreactivity also proved to be specific since it was blocked by bridge peptide, i.e., prodynorphin(186-208), but not by dynorphin $A(1-17)$, dynorphin $\mathrm{B}(1-13), \quad \alpha$-neo-endorphin, Leu-enkephalin, Met-enkephalin, proenkephalin(192-203), or $\beta$-endorphin.

Although some fiber and terminal-like immunoreactivity could be seen in normal, untreated animals, the best results were obtained using animals pretreated with varying doses of colchicine. Increasingly intense perikaryal staining was noted with successively higher doses of colchicine in the cryostat-sectioned, slide-mounted tissue processed for PAP immunocytochemistry. The best results for both perikarya and fibers, however, were obtained using the technique of floating-section PAP immunocytochemistry. In these tissues, intense immunoreactivity could be seen in neuronal perikarya, fibers, and terminals in an animal that was given 2 mg colchicine, intracerebroventricularly. The best perikaryal immunostaining was observed with the dynorphin $B$
(Figs. 1, 3B and C, 6) and bridge peptide (Figs. 2, 3A, 4B and C) antisera, with more intense fiber staining seen using the dynorphin $\mathrm{A}$ antiserum (Figs. 2, 4A, 5).

Neuronal perikarya immunoreactive for prodynorphin peptides are found in numerous brain areas (see Fig. 8 for a summary). With the exception of the magnocellular supraoptic and paraventricular nuclei (Fig. 3), and some lateral hypothalamic area neurons (Fig. 4B), most dynorphin neurons are small and scattered within each nucleus or region (e.g., Fig. 4C). The supraoptic nucleus is densely packed with dynorphin-positive perikarya throughout its rostral-caudal extent (Fig. 3A and B), in parts both lateral and medial to the optic tract. In the paraventricular nucleus, immunoreactive perikarya are seen loosely organized adjacent to the third ventricle both dorsally and ventrally (Fig. $3 \mathrm{~A}$ and $\mathrm{C}$ ). Other hypothalamic areas that contain scattered immunoreactive perikarya include the infundibular, ventromedial, dorsomedial, and medial mammillary nuclei, as well as the lateral hypothalamic area (see Fig. 8). Numerous immunoreactive perikarya are also seen in the medial preoptic area, some occupying a periventricular position. Elsewhere in the diencephalon, scattered immunoreactive perikarya are seen only in the reuniens nucleus of thalamus (Fig. 8).

Numerous, small, dynorphin-positive interneurons are seen in the anterior cingulate cortex (subcallosal gyrus), 


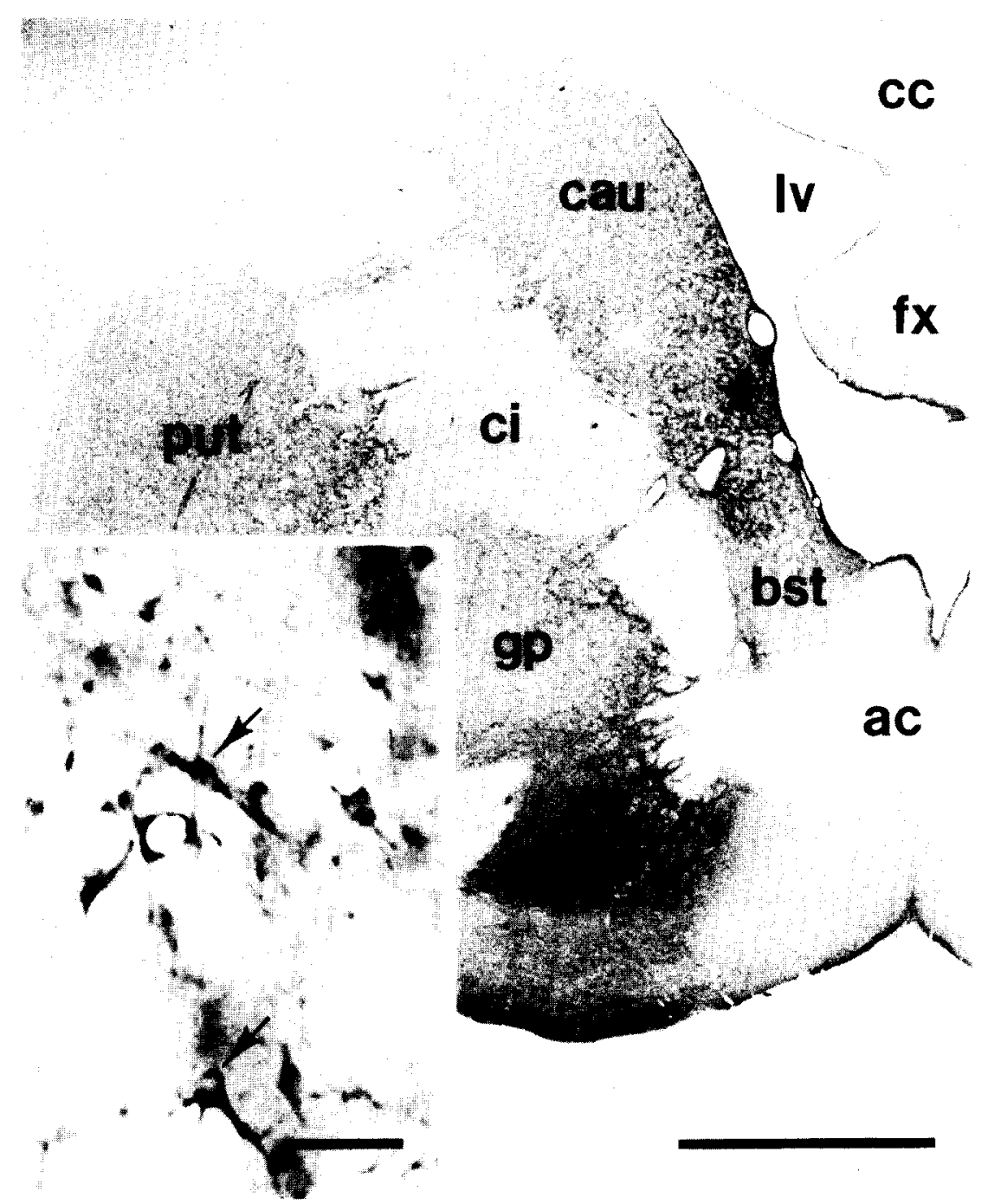

FIG. 2. This frontal view of a section through the telencephalon shows the distribution of dynorphin A immunoreactivity in the basal ganglia. Note the intense staining in the ventral pallidum. The star indicates the ventromedial region of the head of caudate nucleus where numerous dynorphin neurons were seen. A few of these neurons (arrows), immunoreactive for bridge peptide, can be seen in the inset. Bar $=4 \mathrm{~mm}$. Bar (inset) $=50 \mu \mathrm{m}$. ac: anterior commissure, bst: bed nucleus of stria terminalis, cau: caudate, cc: corpus callosum, ci: internal capsule, fx: fornix, gp: globus pallidus, Iv: lateral ventricle, put: putamen, vp: ventral pallidum.

mainly in layers II and III (Fig. 1). In the striatal complex, dynorphin immunoreactive perikarya are seen in the ventromedial aspect of the head of caudate nucleus, adjacent to the lateral ventricle (Fig. 2). No immunoreactive perikarya could be detected in the putamen. Other telencephalic nuclei which contain scattered perikarya include the nucleus accumbens, bed nucleus of stria terminalis, and the central nucleus of amygdala (Fig. 8). In the latter, perikarya are very sparse; only occasional dynorphin-positive neurons are seen in a single section (Fig. 4C).

In brain stem, scattered dynorphin-containing perikarya can be seen in mesencephalic substantia grisea centralis (periaqueductal gray) (Fig. 8). Elsewhere, the dorsal parabrachial nucleus (Fig. 6), nucleus tractus solitarius, and lateral reticular nucleus all exhibit scattered dynorphin-positive neurons. Scattered perikarya are also seen in the vicinity of the locus coeruleus and the mesencephalic trigeminal nucleus, but not within either nucleus. Other positive perikarya are present in ventrolateral pontine reticular formation, at the level of the motor facial nucleus. In the caudal medulla, numerous dynorphin-positive perikarya are situated in the marginal zone as well as deeper layers of the spinal trigeminal nucleus (Fig. 7).

Several areas of the brain contain dynorphin-positive fibers and terminals (see Fig. 8 for a summary). Scattered fibers are seen as rostrally as the anterior cingulate cortex (Fig. 1). In the striatum, scattered fiber immunoreactivity can be seen in the caudate and putamen, the latter exhibiting only light immunoreactivity (Figs. 2, 4A). Dense woolly fiber immunoreactivity, as described before [19], is seen in both 


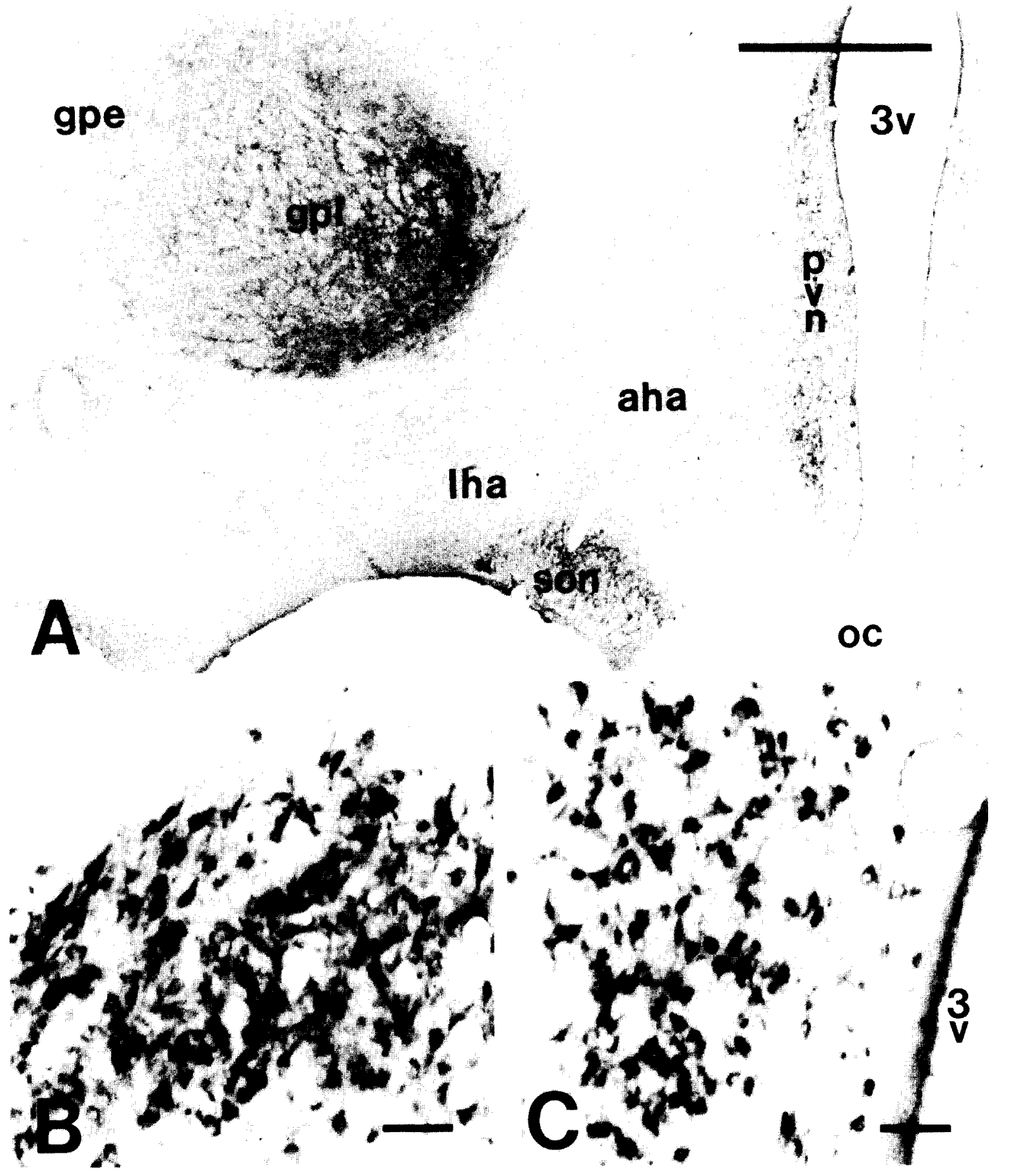

FIG. 3. Panel A shows a frontal section through the hypothalamus and basal ganglia, immunoreactive for dynorphin bridge peptide. Note the intense staining in the internal globus pallidus and perikaryal staining in the magnocellular neurons. In panels $B$ and $C$, dynorphin $B$ immunoreactive magnocellular neurons are shown in the supraoptic (A) and paraventricular (B) nuclei. $\operatorname{Bar}(A)=2 \mathrm{~mm}$. Bars $(B, C)=100 \mu \mathrm{m} .3 \mathrm{v}$ : third ventricle, aha: anterior hypothalamic area, gpe: external globus pallidus, gpi: internal globus pallidus, lha: lateral hypothalamic area, oc: optic chiasm, pvn: paraventricular nucleus, son: supraoptic nucleus.

the external and internal globus pallidus (Figs. 2, 3A, 4A). This dense immunostaining also extends into the ventral pallidum (Fig. 2). By contrast, in the olfactory area, only light immunoreactivity is seen in the region of the islands of Calleja. In most of the other telencephalic and diencephalic re- gions which contain immunoreactive perikarya (see above), varying densities of dynorphin positive fibers are also seen. Of particular interest, immunoreactive varicosities are numerous in the supraoptic and paraventricular nuclei (Fig. $3 B$ and C), as well as the lateral hypothalamic area (Fig. 4B). 

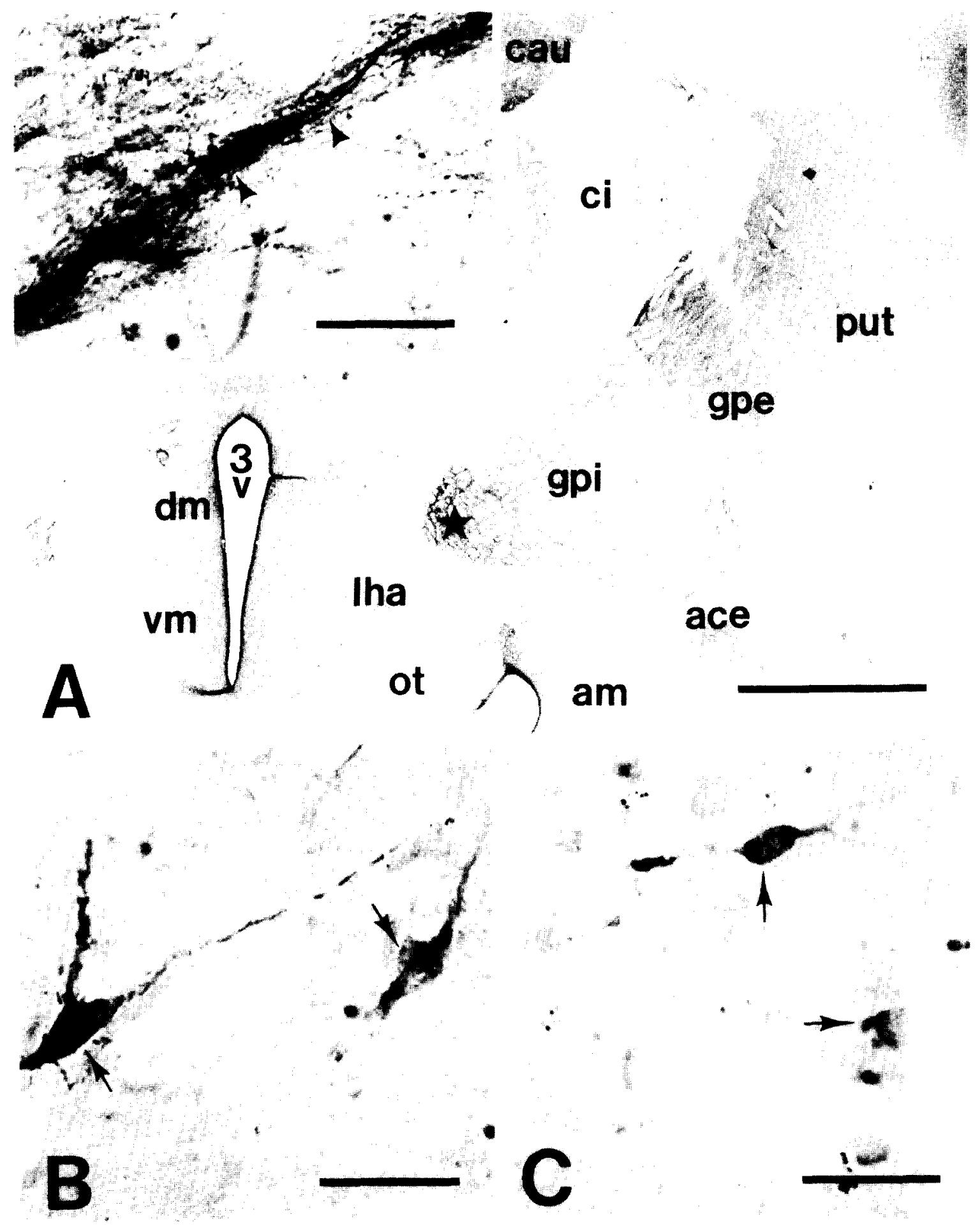

FIG. 4. Panel $\mathrm{A}$ is a frontal section demonstrating dynorphin $\mathrm{A}$ immunoreactivity in the basal ganglia, hypothalamus, and amygdala. Note the intense immunoreactivity in the medial region of the internal globus pallidus (star). This region is magnified in the inset to show woolly fiber immunoreactivity (arrowheads). Note also the immunoreactivity in the central nucleus of amygdala. In panels $B$ and $C$, bridge peptide immunoreactivity can be seen in neuronal perikarya (arrows) and processes in the lateral hypothalamic area $(B)$ and the central nucleus of amygdala $(C)$. Bar $(A)=4 \mathrm{~mm}$. Bar $(A$, inset $)=50$ $\mu \mathrm{m}$. Bars $(B, C)=50 \mu \mathrm{m}$. 3v: third ventricle, ace: central nucleus of amygdala, am: medial nucleus of amygdala, cau: caudate, ci: internal capsule, $\mathrm{dm}$ : dorsomedial nucleus, gpe: external globus pallidus, gpi: internal globus pallidus, lha: lateral hypothalamic area, ot: optic tract, put: putamen, vm: ventromedial nucleus. 


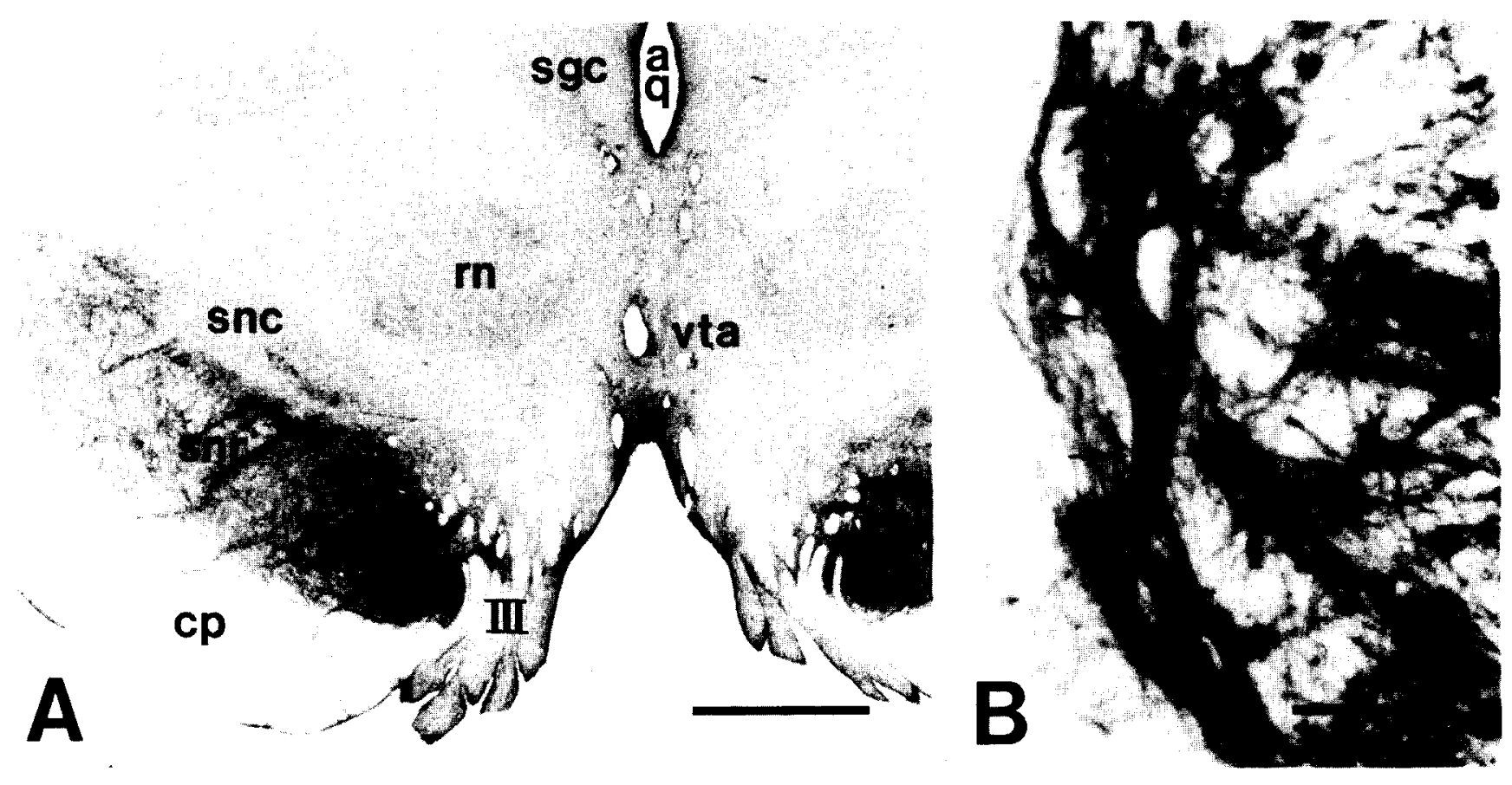

FIG. 5. Dynorphin A immunoreactivity in the substantia nigra pars reticulata, seen in a frontal section through the midbrain (panel A). Note that this immunoreactivity is densest in the more medial aspects of the substantia nigra (star), and appears in the form of long woolly fibers (arrows) and patches, magnified in panel B. Bar $(A)=2 \mathrm{~mm}$. Bar $(B)=200 \mu \mathrm{m}$. III: oculomotor nerve, aq: cerebral aqueduct, cp: cerebral peduncle, rn: red nucleus, sgc: substantia grisea centralis, snc: substantia nigra pars compacta, snr: substantia nigra pars reticulata, vta: ventral tegmental area.

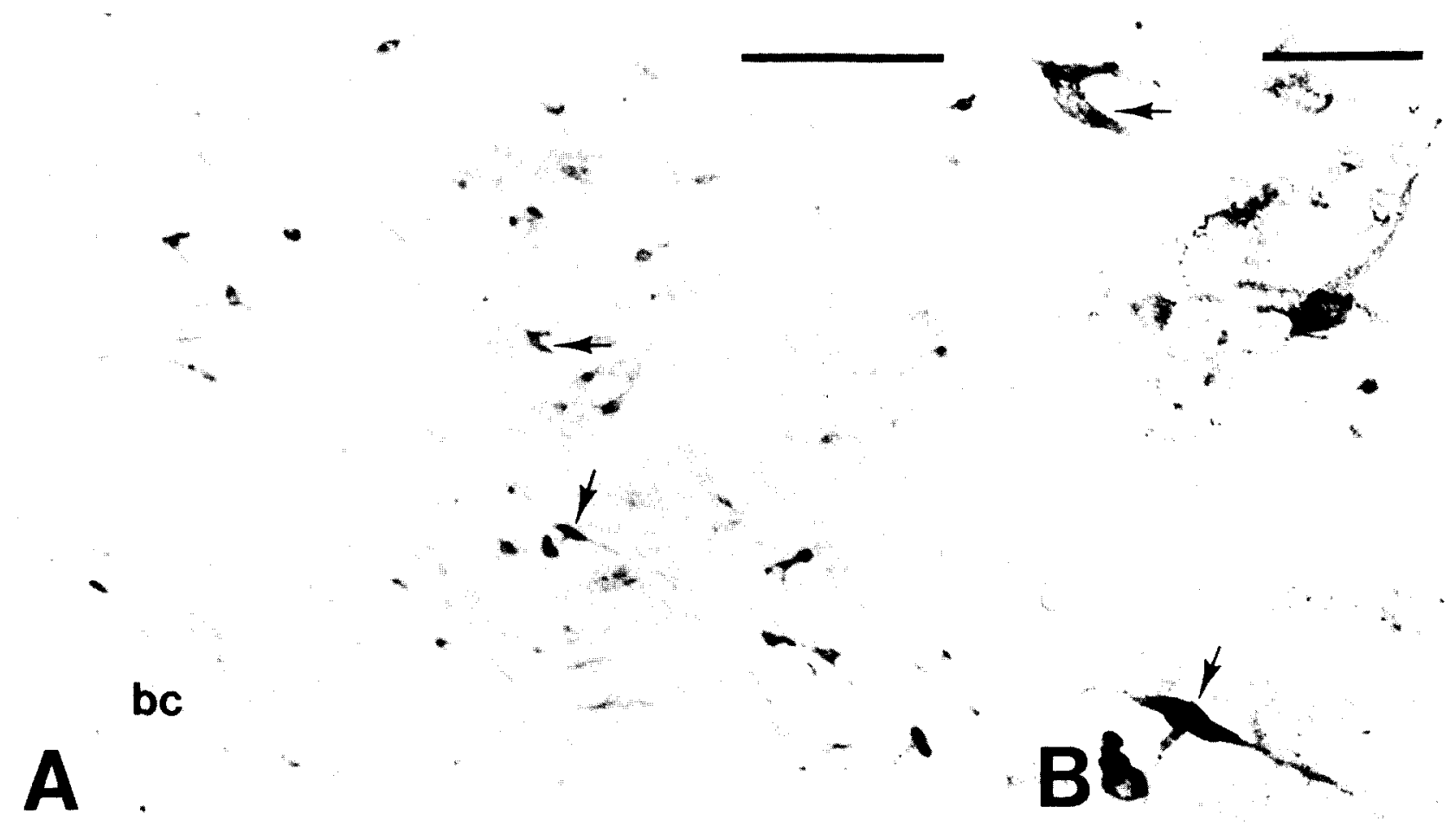

FIG. 6. Panel A shows dynorphin B immunoreactive perikarya in the parabrachial nucleus, in a frontal plane through the rostral pons. A region of the parabrachial nucleus is magnified in panel B to demonstrate two immunoreactive neurons $(\operatorname{arrows}) . B a r(A)=200 \mu \mathrm{m} . B a r(B)=50$ $\mu \mathrm{m}$. bc: brachium conjunctivum. 


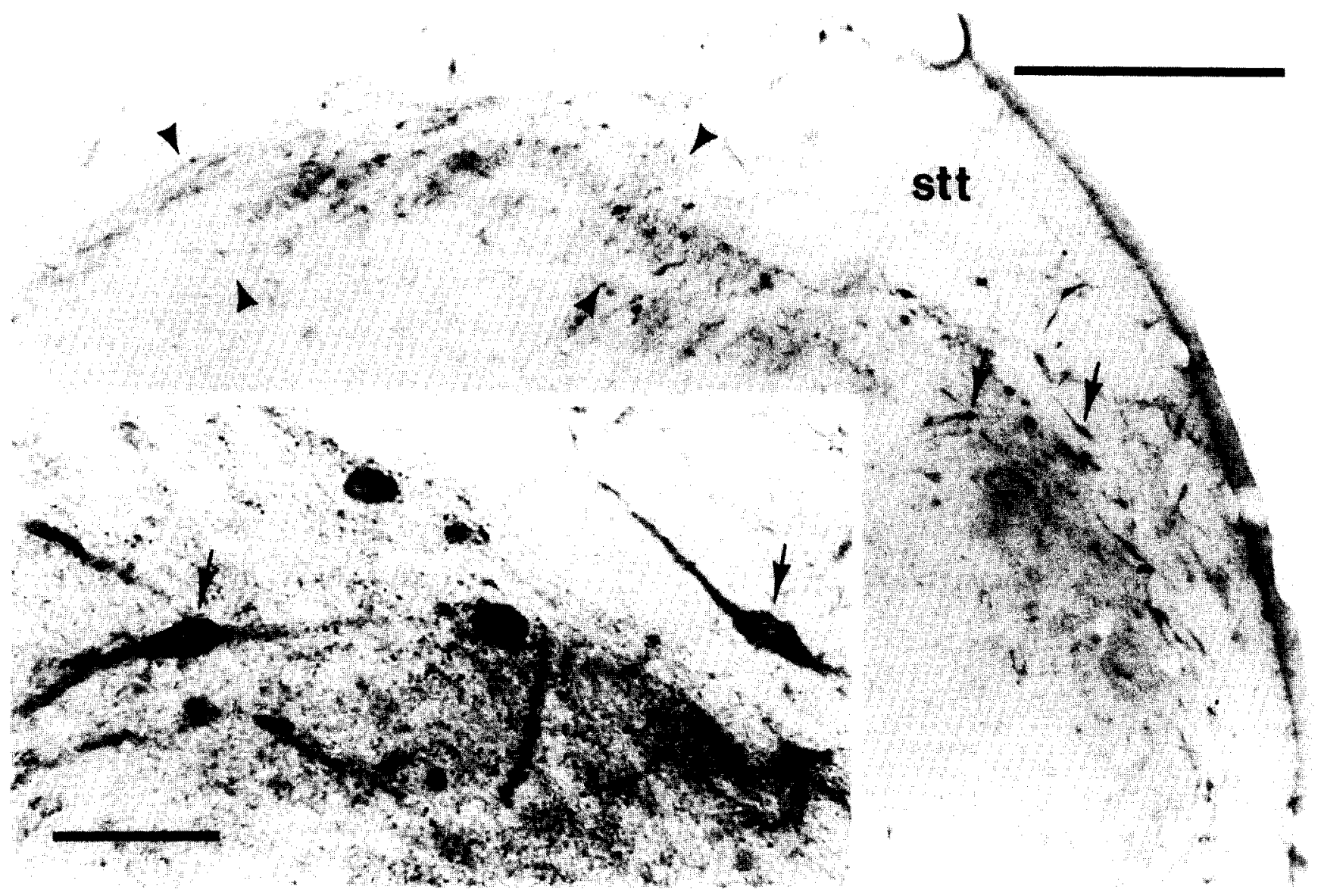

FIG. 7. Dynorphin B immunoreactivity is seen in a frontal section through the caudal medulla. Note the immunoreactivity in the marginal zone (arrowheads) of the spinal trigeminal nucleus. Two immunoreactive neurons (arrows) located in this region are seen magnified in the inset. The right arrow points to a neuron in the spinal trigeminal tract. Bar $=400 \mu \mathrm{m}$. Bar (inset) $=50 \mu \mathrm{m}$. stt: spinal trigeminal tract.

Fibers are also seen in the internal layer of the median eminence. In the thalamus, only light, diffuse immunoreactivity is seen in the anterior nuclei (see Fig. 8).

In the brain stem, by far the densest accumulation of immunoreactive fibers is seen in the substantia nigra pars reticulata (Fig. 5). Here, as in the globus pallidus, woolly fiber immunoreactivity is seen throughout, but is particularly dense more medially (Fig. 5B). Elsewhere in the brain stem, scattered fibers are seen in the substantia grisea centralis, interpeduncular nucleus, and the inferior olivary nucleus. Other scattered fibers are seen in the parabrachial (Fig. 6), locus coeruleus, mesencephalic trigeminal, tractus solitarius, and lateral reticular nuclei. Lastly, in the spinal trigeminal nucleus, immunoreactive varicosities are seen in the marginal zone and to a lesser extent in deeper layers (Fig. 7).

\section{DISCUSSION}

This study investigated the distribution of dynorphin A, dynorphin $B$, and dynorphin bridge peptide or prodynorphin(186-208) in the brain of the adult rhesus monkey, Macaca mulatta. The immunoreactivity seen using all three antisera appeared to be very similarly distributed in all areas of the brain studied. This is consistent with the demonstration of co-synthesis of these peptides from a single precursor, prodynorphin [23], as well as their colocalization within the same neurons in numerous brain regions [61-63, $65,66]$. Some minor differences noted among the three antisera in the intensity of staining is probably due to differences in sensitivity of these antisera, and perhaps also due to the differential concentrations of specific peptide antigens in different parts of the neuron, i.e., cell body vs. axonal projections and terminals. Thus, the observation that dynorphin $\mathrm{B}$ and bridge peptide immunostaining is stronger in neuronal perikarya when compared to that observed using the dynorphin $A$ antiserum, might well be the result of differences in antibody sensitivity and/or the lack of abundance of dynorphin $A$ in perikarya. The latter possibility seems particularly plausible since this antiserum (i.e., anti-dynorphin A) stains terminal innervation fields much more strongly, which might be due to a relatively higher content of dynorphin $\mathrm{A}$ in neuronal terminals. This interpretation is further supported by the biochemical observations of the relative abundance of dynorphin A over dynorphin B in both the rat and monkey substantia nigra [7,8], a terminal field of striato-nigral pro- 


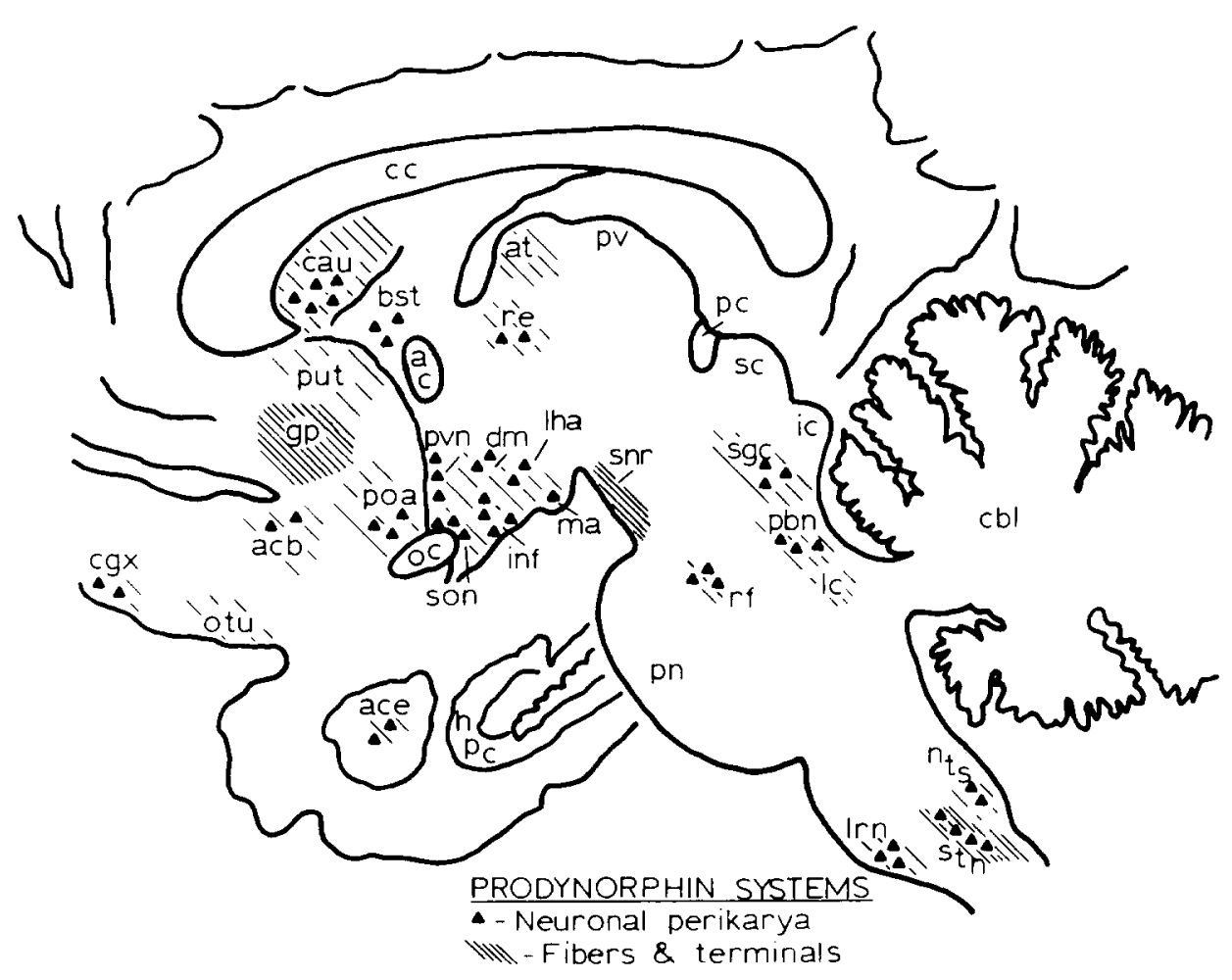

FIG. 8. Schematic summary of prodynorphin peptide systems in the rhesus monkey brain. In this parasagittal view, neuronal perikarya are shown as solid triangles, while fibers and terminals are depicted as diagonal lines. ac: anterior commissure, acb: nucleus accumbens, ace: central nucleus of amygdala, at: anterior nucleus of thalamus, bst: bed nucleus of stria terminalis, cau: caudate, cbl: cerebellum, cc: corpus callosum, cgx: cingulate cortex, $\mathrm{dm}$ : dorsomedial nucleus, gp: globus pallidus, hpc: hıppocampus, ic: inferior colliculus, inf: infundibular nucleus, lc: locus coeruleus, lha: lateral hypothalamic area, Irn: lateral reticular nucleus, ma: medial mammillary nucleus, nts: nucleus tractus solitarius, oc: optic chiasm, otu: olfactory tubercle, pv: periventricular nucleus of thalamus, pc: posterior commissure, put: putamen, pvn: paraventricular nucleus, poa: preoptic area, pbn: parabrachial nucleus, pn: pons, rf: recticular formation, re: reuniens nucleus of thalamus, sc: superior colliculus, snr: substantia nigra pars reticulata, sgc: substantia grisea centralis, son: supraoptic nucleus, stn: spinal trigeminal nucleus.

jections $[10,41,52,72]$. In fact, dynorphin $A(1-17)$ might be a biosynthetic intermediate in several regions of the brain including substantia nigra, with dynorphin $A(1-8)$ being a major end product $[8,64,73]$. However, the dynorphin $A$ antiserum used in the present study equally recognizes dynorphin A(1-8) (see results).

In previous studies of dynorphin immunoreactivity in the rat brain, a consistent finding has been the close anatomical association between perikarya and projections of dynorphin-containing and enkephalin-containing neurons $[30,35,60]$. These observations can now be extended to the rhesus monkey brain as well. In fact, most areas described here to contain dynorphin perikarya and fibers, also contain enkephalin immunoreactive neurons $[17,18]$. However, enkephalin immunoreactivity appears to be more widely distributed than that of dynorphin. For example, areas that have been shown to contain enkephalin but not dynorphin neuronal perikarya include: septal nuclei, basal and medial amygdaloid nuclei, lateral and intermediate mammillary nuclei, periventricular nucleus of thalamus, habenular nuclei, inferior colliculus, interpeduncular nucleus, nucleus trapezoideus, nucleus of the lateral lemniscus, nuclei of the raphe, ventral and dorsal tegmental nuclei, and locus coeruleus (compare the present findings with those of [18]). The other brain regions (with the exception of cerebral cortex, not considered in the latter study) that contain dynorphin neurons also contain enkephalin-positive perikarya. Furthermore, enkephalin projections also appear to be more widespread in the rhesus monkey brain when compared to dynorphin projections (see [17]).

The above observations raise the possibility of coexistence of prodynorphin and proenkephalin in some neurons in the rhesus monkey brain. For example, the existence of both dynorphin and enkephalin immunoreactivity in the hypothalamic supraoptic and paraventricular nuclei may suggest their co-synthesis within magnocellular neurons in this species. However, since detailed colocalization studies have not been carried out in the monkey magnocellular system, it is not clear whether either dynorphin or enkephalin or both exist in the vasopressin or oxytocin producing neurons (see [57]). Leu-enkephalin immunoreactivity has been shown to occur in a small subpopulation of magnocellular paraventricular neurons [6]. In addition, Haber and Elde [18] have reported the existence of Met-enkephalin immunoreactivity in both supraoptic and paraventricular nuclei. These observations lend support for the synthesis of both prodynorphin 
and proenkephalin in monkey magnocellular neurons, although not necessarily within the same cells. However, significant interspecies variations appear to exist in the distribution of proenkephalin and prodynorphin peptides in magnocellular neurons. In the cat hypothalamus, Met-enkephalin immunoreactivity has been noted in some magnocellular neurons, but not colocalized with either vasopressin or oxytocin [36]. In the bovine hypothalamus, Metenkephalin immunoreactivity has been associated with oxytocin neurons [50]. In the rat, however, Leu- and Metenkephalin immunoreactivity appear to be confined to parvocellular paraventricular neurons, whereas all dynorphin antisera tested to date are colocalized within vasopressin neurons in both the supraoptic and paraventricular nucleus [57, 60-63].

Another area of variation in the distribution of dynorphin and enkephalin is seen in the basal ganglia. Considerable species variations have been noted in the distribution of these peptides in the globus pallidus of the rat, cat, monkey, and human $[3,20,21]$. In this structure, enkephalin and dynorphin immunoreactivity occur in dense plexuses of fibers wrapped around the non-immunoreactive dendrites of pallidal neurons. This so-called woolly fiber morphology has been described more extensively elsewhere [19]. In both monkey and human brain, enkephalin immunoreactivity is densely distributed within the external globus pallidus, being less pronounced in the internal region $[1,20,21]$. By contrast, dynorphin immunoreactivity appears equally dense in the medial aspect of the monkey internal globus pallidus. Haber and Watson [20] have further noted differences in the distribution of these two peptides in the ventral striatum, amygdala, bed nucleus of stria terminalis, and substantia nigra of the rat, monkey, and human brain. For example, unlike the rat substantia nigra pars reticulata where enkephalin immunoreactivity is very weak when compared to that of dynorphin, this structure in the monkey and human appears to be densely innervated by both dynorphin and enkephalin fibers [20]. Furthermore, dynorphin immunoreactivity in the monkey pars reticulata is denser medially, in contrast to the more even distribution of dynorphin immunoreactivity within the pars reticulata of rat substantia nigra [30].

Other similarities and differences are apparent in the distribution of prodynorphin peptides in the rhesus monkey and rat brain. Most diencephalic and brain stem nuclei that contain prodynorphin immunoreactive peptides in the rat also exhibit this immunoreactivity in the monkey brain. However, in the rat brain, dynorphin immunoreactive fibers are further distributed in areas that are devoid of immunocytochemically detectable dynorphin in the monkey. These include superior and inferior colliculi, main trigeminal sensory and motor nuclei, facial and vestibular nuclei, nuclei reticularis gigantocelluaris and paragigantocellularis (equivalent of primate magnocellular reticular nuclei), and nuclei raphe dorsalis and raphe magnus. More strikingly, in comparison to rat, the monkey telencephalon is significantly deficient in dynorphin immunoreactivity. We have been able to observe only a few immunoreactive perikarya and fibers in the anterior cingulate cortex of the monkey, whereas large numbers of dynorphin-containing neurons have been reported in the rat cerebral cortex [35]. In the monkey amygdala, only a few dynorphin-positive perikarya can be seen in the central nucleus, whereas in the rat central nucleus of amygdala immunoreactive perikarya are more abundant [30]. Furthermore, we have been unable to detect dynorphin- positive structures in the monkey hippocampus, or dentate gyrus mossy fiber projections onto the pyramidal cells of areas $\mathrm{CA} 2$ and $\mathrm{CA} 3$ as reported in the rat brain $[30,34]$. However, these latter observations have depended upon the use of neurotoxins such as kainic acid and colchicine injected directly into the hippocampus [34] or relatively high doses of colchicine administered intracerebroventricularly $[30,35]$ in order to enhance immunoreactivity in neurons which may contain very low levels of stored peptide. By contrast, the relatively low levels of colchicine used in the present study may have precluded the visualization of small quantities of peptide present in cortical and hippocampal areas. Nevertheless, studies on the distribution of enkephalin in the hippocampus have also noted only scant or no immunoreactivity in either the monkey [17] or the human [1].

Despite these apparent species differences, some of which may be due to procedural variables as indicated above, there are also striking similarities between rat and monkey in the distribution of prodynorphin peptide systems in brain. For example, two of the best defined dynorphin systems, the striato-nigral and magnocellular hypothalamic, appear to be present in both species, indicating the possibility of a similarity and thus conservation of proposed physiological functions of dynorphin, i.e., in extrapyramidal motor and neuroendocrine regulation, respectively. In addition, dynorphin perikarya are present in both species in other hypothalamic nuclei (e.g., lateral hypothalamic area and arcuate or infundibular nucleus), and caudally in the periaqueductal gray (substantia grisea centralis), parabrachial nucleus, nucleus tractus solitarius, lateral reticular nucleus, and spinal trigeminal nucleus. The apparent conservation of dynorphin systems in these structures, which are important in consummatory and reproductive behavior, and organismic responses to pain and stress, suggests that prodynorphin peptides may have a significant physiological role in these fundamental processes, mediated by actions at opioid and perhaps also non-opioid receptors $[54,55]$. The most marked species differences appear to be in systems important for behavioral plasticity, e.g., cerebral cortex and hippocampus, although such apparent differences must be regarded cautiously for technical reasons. Nevertheless, it is possible that the extensive species differences in telencephalic dynorphin systems reflect a divergence of some of the functional roles of prodynorphin peptides in these species. Such divergence is consistent with the finding of widespread differences in the distribution of opioid receptors in rat and rhesus monkey brain $[32,33,56,68]$. Since there are also species and regional differences in the processing of prodynorphin $[7,8]$, it is clear that more intensive studies of the individual dynorphin systems, especially in relation to the peptide forms and opioid receptor subtypes present, will be important to lay the groundwork for understanding the physiological functions of dynorphin in the brain.

\section{ACKNOWLEDGEMENTS}

This work was supported by NIDA Center Grant DA00154 to H.A. and S.J.W., NIMH Training Grant MH15794 to M.E.L., NIH Grant NS20467 to S.N.H., and the Theophile Raphael Fund. We are grateful to Per Kjeldsen of the School of Dentistry for his assistance in the preparation of the macrophotographs. We also wish to thank Mark Fitzsimmons and Sharon Burke for expert technical assistance and Adele Henry for manuscript preparation. 


\section{REFERENCES}

1. Bouras, C., C. H. Taban and J. Constantinidis. Mapping of enkephalins in human brain. An immunohistofluorescence study on brains from patients with senile and presenile dementia. Neuroscience 12: 179-190, 1984.

2. Chavkin, C., C. Bakhit, E. Weber and F. E. Bloom. Relative contents and concomitant release of prodynorphin/ neoendorphin-derived peptides in rat hippocampus. Proc Natl Acad Sci USA 80: 7669-7673, 1983.

3. Chesselet, M.-F. and A. M. Graybiel. Met-enkephalin-like and dynorphin-like immunoreactivities of the basal ganglia of the cat. Life Sci 33: Suppl 1, 37-40, 1983.

4. Cone, R. I., E. Weber, J. D. Barchas and A. Goldstein. Regional distribution of dynorphin and neo-endorphin peptides in rat brain, spinal cord and pituitary. I Neurosci 3: 2146-2152, 1983.

5. Cox, B. M., V. E. Ghazarossian and A. Goldstein. Levels of immunoreactive dynorphin in brain and pituitary of Brattleboro rats. Neurosci Lett 20: 85-88, 1980.

6. DiFiglia, M. and N. Aronin. Immunoreactive Leu-enkephalin in the monkey hypothalamus including observations on its ultrastructural localization in the paraventricular nucleus. $J$ Comp Neurol 225: 313-326, 1984.

7. Dores, R. M. and H. Akil. Steady-state levels of prodynorphinrelated end products in the striatum and substantia nigra of the adult rhesus monkey. Peptide's 6: Suppl 2, 143-148, 1985.

8. Dores, R. M., M. E. Lewis, H. Khachaturian, S. J. Watson and $\mathrm{H}$. Akil. Analysis of opioid and non-opioid end products of pro-dynorphin in the substantia nigra of the rat. Neuropeptides, 5: $501-504,1985$

9. Elde, R., S. Haber, R. Ho, V. Holets, N. deLanerolle, B. Maley, P. Micevych and V. Seybold. Interspecies conservation and variation in peptidergic neurons. Peptides 1: Suppl 1, 21-26, 1980.

10. Feger, J. and A. R. Crossman. Identification of different subpopulations of neostriatal neurones projecting to globus pallidus or substantia nigra in the monkey: A retrograde fluorescence double-labelling study. Neurosci Lett 49: 7-12, 1984.

11. Fischli, W., A. Goldstein, M. Hunkapiller and L. Hood. Two "big" dynorphins from porcine pituitary. Life Sci 31: 1769$1772,1982$.

12. Geis, R., E. Weber, R. Martin and K. H. Voigt. Hypothalamoposterior pituitary system in Brattleboro rats: immunoreactive levels of leucine-enkephalin, dynorphin (1-17), dynorphin (1-8) and alpha-neo-endorphin. Life $S_{c} i$ 31: 1809-1812, 1982.

13. Goldstein, A., W. Fischli, L. I. Lowney, M. Hunkapiller and L. Hood. Porcine pituitary dynorphin: Complete amino acid sequence of the biologically active heptadecapeptide. Proc Natl Acad Sci USA 75: 7219-7223, 1981.

14. Goldstein, A. and V. E. Ghazarossian. Immunoreactive dynorphin in pituitary and brain. Proc Natl Acad Sci USA 77: 6207$6210,1980$.

15. Goldstein, A., S. Tachibana, L. I. Lowney, M. Hunkapiller and L. Hood. Dynorphin-(1-13), an extraordinarily potent opioid peptide. Proc Natl Acad Sci USA 76: 6666-6670, 1979.

16. Gramsch, C., V. Hollt, A. Pasi, P. Mehraein and A. Herz. Immunoreactive dynorphin in human brain and pituitary. Brain Res 233: 65-74, 1982.

17. Haber, S. and R. Elde. The distribution of enkephalin immunoreactive fibers and terminals in the monkey central nervous system: An immunohistochemical study. Neuroscience 7: $1049-1095,1982$

18. Haber, S. and R. Elde. The distribution of enkephalin immunoreactive neuronal cell bodies in the monkey brain. Preliminary observations. Neurosci Lett 32: 247-252, 1982.

19. Haber, S. N. and W. J. H. Nauta. Ramifications of the globus pallidus in the rat as indicated by patterns of immunohistochemistry. Neuroscience 9: 245-260, 1983.
20. Haber, S. N. and S. J. Watson. The comparison between enkephalin-like and dynorphin-like immunoreactivity in both monkey and human globus pallidus and substantia nigra. Life Sci 33: Suppl 1, 33-36, 1983.

21. Haber, S. N. and S. J. Watson. The comparative distribution of enkephalin, dynorphin and substance $P$ in the human globus pallidus and basal forebrain. Neuroscience 14: 1011-1024, 1985.

22. Hollt, V., I. Haarmann, K. Bovermann, M. Jerlicz and A. Herz. Dynorphin-related immunoreactive peptides in rat brain and pituitary. Neurosci Lett 18: 149-153, 1980.

23. Kakidani, H., Y. Furutani, H. Takahashi, M. Noda, Y. Morimoto, T. Hirose, M. Asai, S. Inayama, S. Nakanishi and S. Numa. Cloning and sequence analysis of cDNA for porcine beta-neo-endorphin/dynorphin precursor. Nature 298: 245-249, 1982.

24. Kangawa, K., N. Minamino, N. Chino, S. Sakakibara and H. Matsuo. The complete amino acid sequence of alpha-neoendorphin. Biochem Biophys Res Commun 99: 871-878, 1981.

25. Khachaturian, H., M. E. Lewis, M. D. Fitzsimmons and S. J. Watson. Immunocytochemical studies of dynorphin distribution in the rhesus monkey central nervous system. Soc Neurosci Abstr 10: 590, 1984

26. Khachaturian, H., M. E. Lewis, S. N. Haber, H. Akil and S. J. Watson. Proopiomelanocortin peptide immunocytochemistry in rhesus monkey brain. Brain Res Bull 13: 785-800, 1984.

27. Khachaturian, H., M. E. Lewis, V. Hollt and S. J. Watson. Telencephalic enkephalinergic systems in the rat brain. $J$ Neurosci 3: 844-855, 1983.

28. Khachaturian, H., M. E. Lewis, M. K.-H. Schafer and S. J. Watson. Anatomy of the CNS opioid systems. Trends Neurosci 8: $111-119,1985$.

29. Khachaturian, H., M. E. Lewis and S. J. Watson. Enkephalin systems in diencephalon and brainstem of the rat. J Comp Neurol 220: 310-320, 1983.

30. Khachaturian, H., S. J. Watson, M. E. Lewis, D. Coy, A. Goldstein and H. Akil. Dynorphin immunocytochemistry in the rat central nervous system. Peptides 3: 941-954, 1982.

31. Kilpatrick, D. L., A. Wahlstrom, H. W. Lahm, R. Blacher and S. Udenfriend. Rimorphin, a unique, naturally occurring [Leu]enkephalin-containing peptide found in association with dynorphin and alpha-neo-endorphin. Proc Natl Acad Sci USA 79: $6480-6483,1982$

32. Lewis, M. E., H. Khachaturian, H. Akil and S. J. Watson. Anatomical relationship between opioid peptides and receptors in rhesus monkey brain. Brain Res Bull 13: 801-812, 1984.

33. Lewis, M. E., H. Khachaturian and S. J. Watson. Comparative distribution of opiate receptors and three opioid peptide neuronal systems in rhesus monkey central nervous system. Life $S$ ci 33: Suppl 1, 239-242, 1983.

34. McGinty, J. F., S. J. Henriksen, A. Goldstein, L. Terenius and F. E. Bloom. Dynorphin is contained within hippocampal mossy fibers: Immunochemical alterations after kainic acid administration and colchicine-induced neurotoxicity. Proc Natl Acad Sci USA 80: 589-593, 1983.

35. McGinty, J. F., D. van der Kooy and F. E. Bloom. The distribution and morphology of opioid peptide immunoreactive neurons in the cerebral cortex of rats. $J$ Neurosci 4: 1104-1117, 1984.

36. Micevych, P. and R. Elde. Relationship between enkephalinergic neurons and the vasopressin-oxytocin neuroendocrine system of the cat: An immunohistochemical study. I Comp Neurol 190: 135-146, 1980.

37. Molineaux, C. J. and B. M. Cox. Subcellular localization of immunoreactive dynorphin and vasopressin in rat pituitary and hypothalamus. Life Sci 31: 1765-1768, 1982.

38. Nakao, K. T Yoshimasa, M. Suda, M. Sakamota, Y Ikeda, K. Hayashi and H. Imura. Rimorphin (dynorphin B) exists together with alpha-neo-endorphin and dynorphin (dynorphin $A$ ) in human hypothalamus. Biochem Biophys Res Commun 113: 30-34, 1983. 
39. Nakao, K., T. Yoshimasa, S. Oki, I. Tanaka, Y. Nakai, M. Wakimasu, M. Fujino and H. Imura. Presence of dynorphin-like immunoreactivity in rat pituitary gland and hypothalamus. Regul Pept 2: 201-208, 1981.

40. Palkovits, M., M. J. Brownstein and N. Zamir. Immunoreactive dynorphin and alpha-neo-endorphin in rat hypothalamoneurohypophyseal system. Brain Res 278: 258-261, 1983.

41. Palkovits, M., M. J. Brownstein and N. Zamir. On the origin of dynorphin $\mathrm{A}$ and alpha-neo-endorphin in the substantia nigra. Neuropeptides 4: 193-199, 1984.

42. Pittius, C. W., B. R. Seizinger, A. Pasi, P. Mehraein and A. Herz. Distribution and characterization of opioid peptides derived from proenkephalin $A$ in human and rat central nervous system. Brain Res 304: 127-136, 1984.

43. Przewlocki, R., C. Gramsch, A. Pasi and A. Herz. Characterization and localization of immunoreactive dynorphin, alpha-neoendorphin, Met-enkephalin and substance $P$ in human spinal cord. Brain Res 280: 95-103, 1983.

44. Roth, K. A., E. Weber, J. D. Barchas, D. Chang and J. K. Chang. Immunoreactive dynorphin-(1-8) and corticotropinreleasing factor in subpopulation of hypothalamic neurons. Science 219: 189-191, 1983.

45. Seizinger, B. R., C. Grimm, V. Höllt and A. Herz. Evidence for a selective processing of proenkephalin $B$ into different opioid peptide forms in particular regions of rat brain and pituitary. $J$ Neurochem 42: 447-457, 1984.

46. Sladek, J. R., Jr. and D. L. Hoffman. Differences in biogenic amine distribution in mammalian brain. $J$ Histochem Cytochem 20: $848,1972$.

47. Steward, O., R. B. Goldschmidt and T. Sutula. Neurotoxicity of colchicine and other tubulin-binding agents: A selective vulnerability of certain neurons to the disruption of microtubules. Life Sci 35: 43-51, 1984.

48. Tachibana, S., K. Araki, S. Ohya and S. Yoshida. Isolation and structure of dynorphin, an opioid peptide, from porcine duodenum. Nature 295: 339-340, 1982.

49. Tozawa, F., T. Suda, S. Tachibana, N. Tomori, H. Demura and K. Shizume. Presence of immunoreactive dynorphin in human cerebrospinal fluid. Life Sci 35: 1633-1637, 1984.

50. Vanderhaeghen, J. J., F. Lotstra, D. R. Liston and J. Rossier. Proenkephalin, [Met]enkephalin, and oxytocin immunoreactivities are colocalized in bovine hypothalamic magnocellular neurons. Proc Natl Acad Sci USA 80: 5139-5143, 1983.

51. Vincent, S. R., T. Hökfelt, I. Christensson and L. Terenius. Dynorphin-immunoreactive neurons in the central nervous system of the rat. Neurosci Lett 33: 185-190, 1982.

52. Vincent, S. R., T. Hökfelt, I. Christensson and L. Terenius. Immunohistochemical evidence for a dynorphin immunoreactive striato-nigral pathway. Eur J Pharmacol 85: 251-252, 1982.

53. Von Bonin, G. and P. Bailey. The Neocortex of Macaca Mulatta. Urbana, IL: University of Illinois Press, 1947.

54. Walker, J. M., H. C. Moises, D. H. Coy, G. Baldrighi and H. Akil. Non-opiate effects of dynorphin and des-Tyr-dynorphin. Science 218: 1136-1138, 1982.

55. Walker, J. M., D. E. Tucker, D. H. Coy, B. G. Walker and H. Akil. Des-Tyrosine-dynorphin antagonizes morphine analgesia. Eur J Pharmacol 85: 121-122, 1982.

56. Wamsley, J. K., M. A. Zarbin, W. S. Young, III and M. J. Kuhar. Distribution of opiate receptors in the monkey brain: An autoradiographic study. Neuroscience 7: 595-613, 1982.

57. Watson, S. J., H. Akil, W. Fischli, A. Goldstein, E. Zimmerman, G. Nilaver and T. B. van Wimersma Greidanus. Dynorphin and vasopressin: Common localization in magnocellular neurons. Science 216: 85-87, 1982.
58. Watson, S. J., H. Akil, V. E. Ghazarossian and A. Goldstein. Dynorphin immunocytochemical localization in brain and peripheral nervous system. Preliminary studies. Proc Natl Acad Sci USA 78: 1260-1263, 1981.

59. Watson, S. J., H. Akil, H. Khachaturian, E. Young and M. E. Lewis. Opioid systems: anatomical physiological and clinical perspectives. In: Opioids: Past, Present and Future, edited by H. O. J. Collier, J. Hughes, M. J. Rance and M. B. Tyers. London: Taylor and Francis Ltd., 1984, pp. 145-178.

60. Watson, S. J., H. Khachaturian, H. Akil, D. H. Coy and A. Goldstein. Comparison of the distribution of dynorphin systems and enkephalin systems in brain. Science 218: 1134-1136, 1982.

61. Watson, S. J., H. Khachaturian, D. Coy, L. Taylor and H. Akil Dynorphin is located throughout the CNS and is often colocalized with alpha-neo-endorphin. Life $S_{c} i$ 31: 1773-1776. 1982.

62. Watson, S. J., H. Khachaturian, L. Taylor, W. Fischli, A Goldstein and $H$. Akil. Pro-dynorphin peptides are found in the same neurons throughout rat brain: Immunocytochemical study. Proc Natl Acad Sci USA 80: 891-894, 1983.

63. Weber, E. and J. D. Barchas. Immunohistochemical distribution of dynorphin $B$ in rat brain: Relation to dynorphin $A$ and alpha-neo-endorphin systems. Proc Natl Acad Sci USA 80: $1125-1129,1983$.

64. Weber, E.. C. J. Evans and J. D. Barchas. Predominance of the amino-terminal octapeptide fragment of dynorphin in rat brain regions. Nature' 299: 77-79, 1982.

65. Weber. E., K. A. Roth and J. D. Barchas. Colocalization of alpha-neo-endorphin and dynorphin immunoreactivity in hypothalamic neurons. Bioc'hem Biophys Res Commun 103: 951-958, 1981.

66. Weber, E., K. A. Roth and J. D. Barchas. Immunohistochemical distribution of alpha-neo-endorphin/dynorphin neuronal systems in rat brain: Evidence for colocalization. Proc Natl Ac ad S i USA 79: 3062-3066, 1982.

67. Weber, E., K. A. Roth, C. J. Evans, J. K. Chang and J. D. Barchas. Immunohistochemical localization of dynorphin (I-8) in hypothalamic magnocellular neurons: evidence for absence of proenkephalin. Life Sci 31: 1761-1764, 1982.

68. Wise, S. P. and M. Herkenham. Opiate receptor distribution in the cerebral cortex of the rhesus monkey. Scienc' 218: 387-389, 1982.

69. Zamir, N., M. Palkovits and M. J. Brownstein. Distribution of immunoreactive dynorphin in the central nervous system of the rat. Brain Res 280: 81-93, 1983.

70. Zamir, N., M. Palkovits and M. J. Brownstein. Distribution of immunoreactive dynorphin Al-8 in discrete nuclei of the rat brain: comparison with dynorphin A. Brain Res 307: 61-68, 1984.

71. Zamir, N., M. Palkovits, E. Weber and M. J. Brownstein. Distribution of immunoreactive dynorphin $B$ in discrete areas of the rat brain and spinal cord. Brain Res 300: 121-127, 1984.

72. Zamir, N.. M. Palkovits, E. Weber, E. Mezey and M. J. Brownstein. A dynorphinergic pathway of Leu-enkephalin production in rat substantia nigra. Nature 307: 643-645, 1984.

73. Zamir, N., E. Weber, M. Palkovits and M. Brownstein. Differ ential processing of prodynorphin and proenkephalin in specific regions of the rat brain. Proc Natl Acad $S_{C} i$ USA 81: $6886-6889,1984$ 